\title{
Food for Thought: The Effects of Nutritional Support on Outcomes in Hospitalized Elderly Patients and the Critically Ill
}

\author{
Jonathan Cohen, ${ }^{1,2}$ Miriam Tehilla, ${ }^{3,4}$ Ronit Anbar, ${ }^{5}$ and Pierre Singer ${ }^{1,2}$ \\ ${ }^{1}$ Department of General Intensive Care, Rabin Medical Center, Campus Beilinson, 49100 Petah Tikva, Israel \\ ${ }^{2}$ Sackler Faculty of Medicine, Tel Aviv University, Tel Aviv, Israel \\ ${ }^{3}$ Nursing Department, Steyer School of Health Professions, Sackler Faculty of Medicine, Tel Aviv University, Tel Aviv, Israel \\ ${ }^{4}$ Rabin Medical Center, Campus Beilinson, Clalit Health Services, 49100 Petah Tikva, Israel \\ ${ }^{5}$ Nutrition Unit, Rabin Medical Center, 49100 Petah Tikva, Israel
}

Correspondence should be addressed to Jonathan Cohen; jdcspc@gmail.com

Received 29 December 2013; Accepted 2 July 2014; Published 16 July 2014

Academic Editor: Rosalind Elliott

Copyright (c) 2014 Jonathan Cohen et al. This is an open access article distributed under the Creative Commons Attribution License, which permits unrestricted use, distribution, and reproduction in any medium, provided the original work is properly cited.

The provision of adequate nutritional support appears to be essential for critically ill patients and other groups of patients at high risk for having malnutrition. In this review paper we describe our recent research regarding the amount of energy to be provided, how this should be assessed, and the beneficial effects of specialized nutritional support. We have shown that repeated measurements of energy expenditure using indirect calorimetry capture the dynamic energy changes characteristic of hospitalized patients. The provision of energy according to these measurements was associated with lower hospital mortality in critically ill patients when compared to patients receiving a fixed energy intake. A similar study performed in geriatric patients revealed a significant reduction in the number of infections when energy was provided according to repeated measurements. We have also shown that a diet enriched with eicosapentaenoic acid and gamma-linolenic acid improved oxygenation and lung dynamics and decreased ventilation duration in ICU patients with acute lung injury and ARDS. A similarly enriched diet together with micronutrients resulted in significantly less progression of existing pressure ulcers in ICU patients compared to an isonitrogenous, nutrient-sufficient formula. This may be related to an increase in the percentage of positive lymphocyte and granulocyte adhesion molecules.

\section{Introduction}

Guidelines have recommended the provision of adequate nutritional support for hospitalized patients, both for critically ill patients in the intensive care unit (ICU) and for other groups of patients at high risk for having malnutrition, either preexisting at admission or developing during their hospital stay. For ICU patients, it is recommended that nutrition should be provided early after admission to the hospital, ideally within the first $24 \mathrm{~h}$, and preferably by the enteral route where this is possible [1-4]. However, some questions regarding nutrition support remain controversial, including the amount of energy to be provided, how this should be assessed, and the beneficial effects of specialized nutritional support.

In this review paper, we will describe our recent research in this area, specifically the beneficial effects of optimizing energy requirements to be delivered to both ICU patients and another population at risk for undernutrition, namely, elderly patients undergoing hip replacement. In addition, we will describe the beneficial effects of specialized nutrition on pulmonary function and pressure ulcer development and progression in critically ill patients.

\section{The Beneficial Effects of Optimizing Energy Delivery}

Critically ill patients frequently incur an energy debt. Factors contributing to this include the absence of feeding protocols, physical factors interfering with nutritional delivery such as impaired gastric motility, and frequent interruptions due to the presence of diarrhea or the performance of procedures, such as surgery or radiological examinations [5-7]. In addition, the inadequate assessment of ongoing and changing 
TABLE 1: Severe lung injury study: summary of energy and protein parameters during the study period and primary outcome in the per protocol analysis.

\begin{tabular}{lcc}
\hline Parameter & $\begin{array}{c}\text { Study group } \\
(n=56)\end{array}$ & $\begin{array}{c}\text { Control group } \\
(n=56)\end{array}$ \\
\hline Mean REE (kcal/day) & $1.976 \pm 468$ & $1,838 \pm 468$ \\
Mean energy delivered/day (kcal/day) & $2.086 \pm 460$ & $1,480 \pm 356$ \\
Mean enterally delivered energy/day & $1,515 \pm 756$ & $1,316 \pm 456$ \\
(kcal/day) & & \\
Mean delivered parenteral nutrition & $571 \pm 754$ & $164 \pm 294$ \\
delivered/day (kcal/day) & $76 \pm 16$ & $53 \pm 16$ \\
Mean protein delivered/day (g/day) & $186 \pm 206$ & $-312 \pm 481$ \\
Mean daily energy balance (kcal) & $2,008 \pm 2,177$ & $-3,550 \pm 4,591$ \\
Cumulative energy balance (kcal) & $15.7 \pm 883$ & $-3,895 \pm 4,144$ \\
Maximum negative energy balance (kcal) & $119.6 \pm 21.8$ & $127.3 \pm 33.7$ \\
Daily mean blood glucose (mg/dl) & 28.5 & 48.2 \\
Hospital mortality (\%) & & 0.001 \\
\hline
\end{tabular}

nutritional needs may contribute significantly to inadequate intake. Large energy deficits may result in increased infectious complications and prolonged mechanical ventilation as well as ICU stays [8-10]. Energy requirements are most widely assessed by measuring resting energy expenditure (REE) using predictive equations like the consensus statement of the American College of Chest Physicians (ACCP) recommendation, which calculates REE as a multiple of total body weight [11]. However, studies suggest that these equations appear to be less accurate than the results obtained from direct measurement of the REE using indirect calorimetry (IC) [12]. We have performed 2 recent studies to assess the benefit of more accurately measuring energy requirements in an ongoing manner and correlated this with clinical outcomes.

2.1. Critically Ill Patients with Severe Lung Injury. In the first study, a prospective randomized trial [13], we assigned consecutive patients who were mechanically ventilated and expected to have an ICU stay of more than three days to 2 groups within 48 hours of admission to our adult ICU: a tight calorie group $(n=65)$, comprised of patients who received calories with an energy goal determined by repeated REE measurements using IC (Deltatrac II Metabolic Monitor, Datex-Engstrom, Finland); and a control group $(n=65)$, comprised of patients with an energy goal based on a single determination of a weight-based formula, namely, $25 \mathrm{kcal} / \mathrm{kg} /$ day. EN was commenced with the aim of reaching the energy goal within $24 \mathrm{~h}$ of entering the study. Supplemental parenteral nutrition was used to make up any energy shortfall. IC measurements were repeated in both groups every $48 \mathrm{~h}$. Results were used to adjust the energy prescription in the study group, whereas the energy prescription in the control group was kept constant according to the initial assessment of energy requirements.

A summary of energy and protein parameters during the study period in the perprotocol analysis is shown in Table 1. The energy targets assessed by IC changed significantly $(P=$ 0.008) over time for the first 10 days studied in the study group. The positive energy balance and higher protein intake noted in the study group translated into clinical benefits. Thus, a Kaplan-Meier curve for the per protocol analysis showed that hospital mortality was significantly lower in the study group $(P=0.023)$ (Table 1$)$. Table 2 shows outcome results for the ITT analysis. The Kaplan-Meier curve demonstrated a trend toward lower hospital mortality in the study group $(P=0.058)$. ICU mortality was not significantly different between the 2 groups $(P=0.64)$. This difference is probably related to the fact that nutritional interventions may require more time to become apparent and not be expected to impact on short-term ICU variables. Survival at 60 days was also significantly better in the study group $(P=0.023)$. SOFA score was significantly lower in the study group at day 3 compared to the control group $(P=0.027)$. We did find that length of ventilation and length of ICU stay were both significantly longer in the study group $(P=0.01$ and $P=0.02$, resp.). These findings may be related to the increased calorie related metabolic load in this group. In addition, the total infection rate was higher in the study group $(P=0.05)$, mainly related to a trend for a higher incidence of ventilator-associated pneumonia $(P=0.08)$ which may be related to the early delivery and increased amount of EN the study patients received. Similar findings have been reported in a retrospective study which showed that early enteral feeding was associated with improved ICU and hospital mortality despite an increased risk of VAP [14]. We concluded that a bundle comprising actively supervised nutritional intervention and providing near target energy requirements based on repeated energy measurements using both EN and PN was achievable in a general ICU and may be associated with lower hospital mortality. However, this was also associated with prolonged duration of mechanical ventilation and ICU stay.

\subsection{Optimizing Energy Delivery after Hip Surgery in Geriatric} Patients. Hip fractures remain a significant health risk in the elderly population in Western society. Thus, in the United States, the mean annual number of hip fractures in 2005 was 
TABLE 2: Severe lung injury study: outcome measures in the intention to treat analysis.

\begin{tabular}{lccc}
\hline Parameter & $\begin{array}{c}\text { Study group } \\
(n=65)\end{array}$ & $\begin{array}{c}\text { Control group } \\
(n=65)\end{array}$ & $P$ value \\
\hline SOFA score at 3 days & $5.44 \pm 2.76$ & $7.04 \pm 4.25$ & 0.027 \\
ICU mortality (\%) & 24.6 & 47.7 & 0.64 \\
Hospital mortality (\%) & 32.3 & $48.1 \pm 7.6$ & 0.058 \\
Sixty-day survival (\%) & $57.9 \pm 9.9$ & $10.5 \pm 8.3$ & 0.023 \\
Length of ventilation (days) & $16.1 \pm 14.7$ & $11.7 \pm 8.4$ & 0.03 \\
Length of ICU stay (days) & $17.2 \pm 14.6$ & 20 & 0.04 \\
Infectious complication $(n)$ & 37 & 9 & 0.05 \\
\multicolumn{1}{l}{ VAP $(n)$} & 18 & 0.08 \\
\hline
\end{tabular}

VAP: ventilator-associated pneumonia; SOFA: sequential organ failure assessment.

957.3 per 100000 for women and 414.4 for men [15]. These injuries degrade quality of life and increase both morbidity and mortality $[15,16]$.

One of the factors which might influence the outcome of these patients is their nutritional status. In this regard, up to half of elderly patients with hip fractures are already malnourished on admission to hospital and protein energy malnutrition appears to be more common in older patients with hip fractures than age-matched controls [17, 18]. In addition to the effects of preexisting undernutrition, lean body mass may be further depleted by the inflammatory response to injury, which leads to a catabolic state characterized by nitrogen loss and insulin resistance [18]. This is evident immediately after the injury and may continue for up to 3 months after surgery. Finally, undernutrition may be further aggravated by lower than required intake of energy during the hospital stay. This state of undernutrition may impact outcome. Negative effects include muscle wasting and weakness, impairing mobility, and predisposition to decubitus ulcers and pulmonary complications (including atelectasis and pneumonia) as well as impaired immune responses further predisposing to an increase in postoperative infections $[19,20]$.

We undertook a study to evaluate whether nutritional support guided by repeated measurements of REE improved outcomes in geriatric patients following surgery for hip fractures and compared this to usual nutritional therapy [21]. We included consecutive patients older than 65 years who were admitted to the unit following hip fracture within 48 hours of the injury and in whom orthopedic surgery was considered the treatment of choice. Patients were randomly assigned to 2 groups, within $48 \mathrm{~h}$ of the injury and prior to surgery. The study group, namely, the tight calorie group $(n=22)$ received calories started $24 \mathrm{~h}$ after surgery with an energy goal determined by repeated REE measurements using indirect calorimetry and the amount adjusted to make up the difference between energy received from hospital food and measured energy expenditure. The difference was made up by the addition of oral nutritional supplements (ONS) in the form of Ensure plus (Abbott Laboratories) or Glucerna (Abbott Laboratories). The control group $(n=28)$ received usual hospital food and a fixed dose of ONS if already prescribed prior to hospitalization. The patient, family, and caregivers were educated regarding the importance of nutritional support and more attention was given to personal food preferences. The nutrient intake of each patient was monitored by the research team on a daily basis.

Our results are shown in Table 3. There was no significant difference in the nutritional assessment between the 2 groups at baseline regarding their nutritional status. Patients in the intervention group had a significantly higher mean daily intake of energy and protein compared to the control group so that their calculated daily energy balance was significantly more positive from the 3rd to the 10th day of the study. The mean daily energy delivered was significantly higher in the intervention group and was associated with a significantly less negative cumulative energy balance. The total complication rate was significantly lower in the intervention group compared to the control group mainly due to a reduction in the number of infectious complications. In particular, there were 9 cases of pneumonia in the control group compared to none in the intervention group. Finally, regarding mortality, 2 patients in the control group died (one from sepsis and the other following a cerebrovascular accident), while none died in the intervention group. This difference was not significant $(P=1.0)$. For the whole group, a significant negative correlation was found between the cumulative energy balance and total complication rate $(P=0.003)$ as well as for length of hospital stay $(P=0.049)$.

It should be stressed that the improved energy delivery in the intervention group was a function of the intensity of the nutritional intervention generated by the defined and dynamic energy goal. Thus, it was possible to achieve neartarget energy intakes by repeated measures of REE under the close supervision of the study dietician. This should be compared to the control group where patients receiving usual care and not under active supervision of a dietician incurred a significant negative energy balance. The importance of a proactive approach with the appropriate staff dedicated to the delivery of adequate nutrition cannot be stressed enough. This study adds further support to the importance of an adequate nutritional intervention in this often malnourished and frail population at risk for significant postoperative complications. 
TABLE 3: Nutritional and outcome results of geriatric patients following hip fractures.

\begin{tabular}{lccc}
\hline Parameter & $\begin{array}{c}\text { Study group } \\
(n=22)\end{array}$ & $\begin{array}{c}\text { Control group } \\
(n=28)\end{array}$ & $P$ value \\
\hline Well nourished, \% & 63.6 & 64.3 & 35.7 \\
At risk of malnutrition, \% & 36.4 & $777.1 \pm 301.2$ & 0.597 \\
Mean energy delivered/day (kcal) & $1121.3 \pm 299.1$ & $-4975.5 \pm 4368$ & 0.632 \\
Cumulative energy balance (kcal) & $-1229.9 \pm 1763$ & 64.3 & 0.001 \\
Total complications rate, \% & 27.3 & 50 & 0.001 \\
$\quad$ Infectious complications & 13.6 & $12.5 \pm 5.5$ & 0.012 \\
Duration of hospitalization, days & $10.1 \pm 3.2$ & 2 & 0.008 \\
Mortality, $n$ & 0 & & 1.0 \\
\hline
\end{tabular}

TABLE 4: Outcome results in ventilated patients with acute lung injury receiving a control formula or enteral diet enriched with eicosapentaenoic acid and gamma-linolenic acid.

\begin{tabular}{lcc}
\hline Parameter & $\begin{array}{c}\text { Study group } \\
(n=46)\end{array}$ & $\begin{array}{c}\text { Control group } \\
(n=49)\end{array}$ \\
\hline $\mathrm{PaO}_{2} / \mathrm{FiO}_{2}$ ratio & & $214.3 \pm 56.4$ \\
$\quad$ Day 4 & $317.3 \pm 99.5$ & $236.3 \pm 79.8$ \\
$\quad$ Day 7 & $296.5 \pm 165.3$ & -9 \\
Static compliance (mL/mbar) & & 0.05 \\
$\quad$ Change from day 1 to day 7 & +5.1 & +0.05 \\
Airway resistance (mbar/L/sec) & & +7 \\
$\quad$ Change from day 1 to day 7 & -3 & $166.8 \pm 5.2$ \\
Duration of ventilation (hours) at day 7 & $160.4 \pm 15.2$ & $<0.05$ \\
\hline
\end{tabular}

\section{Modulating Outcome by Nutritional Interventions}

3.1. Acute Lung Injury. Acute lung injury (ALI) is an abrupt pathologic process in the lungs, often seen as part of a persistent systemic syndrome of inflammation. It is characterized by increased permeability in the lung unexplained by pulmonary capillary hypertension and by hypoxemia resistant to oxygen therapy regardless of the positive endexpiratory pressure (PEEP) [22]. Bilateral infiltrates are noted on chest radiographs, combined with high levels of albumin in the alveolar fluid [23]. The severe form is termed acute respiratory distress syndrome (ARDS).

Dietary fish oil containing eicosapentaenoic acid (EPA) and gamma-linolenic acid (GLA) may modulate proinflammatory eicosanoid and prostaglandin E1 production. Indeed, rats fed a diet enriched with EPA and GLA showed both reduced lung microvascular protein permeability after endotoxin administration and improved oxygenation $[24,25]$.

3.1.1. Beneficial Effects of Diet Enriched with EPA, GLA, and Antioxidants in ALI/ARDS. In a prospective randomized study, we examined the effects of an enteral diet enriched with EPA, GLA, and antioxidants (EPA + GLA diet) in patients with ALI/ARDS hospitalized in the ICU [26]. Patients with ALI/ARDS according to the American-European Consensus Conference on ARDS [22] were randomized to control and $\mathrm{EPA}+\mathrm{GLA}$ diet groups. The control group $(n=49)$ received a diet that was a ready-to-feed, high-fat, low-carbohydrate, enteral formula (Pulmocare, Ross Laboratories, Chicago, IL). The study group $(n=46)$ received a formula (Oxepa, Ross Laboratories) which differed from the control group diet only in lipid composition (supplemental GLA and EPA) and in the level of antioxidants, while the caloric and nitrogenous contents were identical. All participants were started on enteral feeding through a nasogastric, duodenal, or jejunal tube within $24 \mathrm{~h}$ of ICU admission. In both groups, feeding was adjusted to achieve $\geq 50 \%$ of the measured resting energy expenditure $(\mathrm{REE}) \times 1.2$ on the first day and $70 \% \mathrm{REE} \times$ 1.2 from the second day. Indeed, all patients included in the study were fed successfully for $\geq 14$ days through the gastric, duodenal, or jejunal route, and none was dropped because of formula-related safety concerns. Mechanical ventilation was targeted to achieve an oxygen saturation of $\geq 90 \%$, peak airway pressure of $<35 \mathrm{~cm} \mathrm{H}_{2} \mathrm{O}$, and tidal volume of $<7 \mathrm{~mL} / \mathrm{kg}$.

The results are shown in Table 4. Oxygenation was significantly higher in the EPA + GLA group on day 4 and on day $7(P=0.05)$, but this advantage was lost by day 14 or at discharge. Patients in the study group showed an improvement in static compliance from day 1 through day 7 , whereas a decrease was seen in the control group $(P<0.05)$. The day 7 values were significantly higher in the EPA + GLA group $(P<0.05)$. Airway resistance decreased in the EPA + GLA group, again significantly more than in the control group $(P<0.05)$. Patients in the EPA + GLA group had 
a significantly shorter length of ventilation (LOV) expressed in hours free from ventilation $(P<0.05)$, while length of ICU stay (LOS) and length of hospital stay were similar in the two groups. Overall survival assessed by a Kaplan-Meier curve was also similar in the two groups.

We concluded from our study that a diet enriched with $\mathrm{EPA}+\mathrm{GLA}$ improved oxygenation and lung dynamics and also morbidity related to the lung condition, decreasing the LOV in the ICU. The effects of EPA and GLA in ALI may be related to the modulation of arachidonic acid metabolism, which enhances the production of more anti-inflammatory eicosanoids. These changes may interfere with the alveolar membrane and neutrophil stimulation of mediators and with prostaglandin synthesis.

3.2. Pressure Ulcers. Critical illness confers susceptibility to the development and persistence of pressure ulcers.

This may be related to several risk factors, including infusions of norepinephrine, scores greater than 13 on the Acute Physiology and Chronic Health Evaluation II, frequent fecal incontinence, anemia, and prolonged ICU stay. In addition, immobility, disturbed sensory perception, 4 and malnutrition, which hampers immune function and wound healing, also increase the risk for pressure ulcers [27, 28]. Finally, impaired nutrition may influence tissue vulnerability to extrinsic factors such as pressure. Indeed, a significant proportion of ICU patients will develop pressure ulcers, in addition to those who present with these lesions on admission. A study which reviewed the literature for the period 2000-5, focusing on the prevalence and incidence of pressure ulcers in intensive care patients, found that while there were variations in intensive care settings ranging from $4 \%$ in Denmark to $49 \%$ in Germany, the overall incidence ranged from 38 to $124 \%$ [29]. These pressure ulcers are associated with increased length of hospitalization and healthcare costs [30].

Wound healing is a complex, multistage process by which tissue integrity is restored following injury or infection. The process comprises a series of events, including a coagulation phase, an inflammatory phase, and a final repair phase [31]. The inflammatory phase plays an essential role in preventing infection, as also an equally essential role in aiding in the tissue repair process. This physiological repair response requires a complex and dynamic interplay of several cell types, including local tissue and recruited haematopoietic cells. Blood cell migration into the wound involves attachment to the endothelial cells and extravasation, a process which is regulated mainly by chemokines and cellular adhesion molecules (CAM). These CAM, integrins, and selectins direct leucocyte-endothelium interactions, transendothelial migration of leucocytes, and leucocyte trafficking in general [32]. The selectins are involved in the initial phase of inflammatory process, by enabling the rolling of leucocytes to resist the sheer force of the blood stream. Thereafter, the activation of integrins results in increased affinity of their ligands on endothelial cells, thus ensuring tight binding of leucocytes to the vascular endothelium so that transendothelial leucocyte migration may follow [32]. Their importance in wound healing was clearly demonstrated by Cruse et al. [33] who showed that delayed healing of pressure ulcers in spinal cord injury patients could be attributed to reduced CAM expression, impaired cell-cell interaction, and lack of extracellular matrix structural and functional protein. Among other compounds, lipids, especially the n-3 long chain PUFA (n-3-LC-PUFA), have been shown to influence the immune response and therefore have an effect on wound healing. Thus, PUFA deficiency has been shown to result in impaired wound healing in patients [34], as well as in rats, who received an essential fatty acid-deficient diet [35].

\subsubsection{Prevention of Pressure Ulcer Progression in Critically Ill} Patients. In a randomized prospective study of 40 critically ill patients in the ICU, we assessed the impact of fish oil- and micronutrient-enriched formula on the expression of adhesion molecules on peripheral blood leucocytes and correlated this with the healing of pressure ulcers in critically ill patients [36]. Patients were randomly allocated to receive either fish oil and micronutrient-enriched enteral nutrition (Oxepa; Abbott, Chicago, IL, USA-the intervention group, $n=20$ ) or an isonitrogenous formula (Jevity; Abbott-the control group, $n=20$ ). The quantity of nutritional formula prescribed was determined by the measurement of resting energy expenditure as assessed by indirect calorimetry. There was no significant difference in the mean protein intake over the study period between the two groups $(66 \cdot 1 \mathrm{~g} / \mathrm{d}$ for the study group v. $65 \cdot 1 \mathrm{~g} / \mathrm{d}$ for the control group).

The percentage of positive adhesion molecules was measured by flow cytometric analysis, while the diagnosis of pressure ulcers both before enrolment and during the ICU stay was assessed by the Pressure Ulcer Scale for Healing tool score, a noninvasive clinical aid that attributes a severity score to a pressure ulcer [37].

Our results (Table 5) showed that patients with pressure ulcers who received an n-3-LC-PUFA and micronutrientenriched nutritional formula showed an increase in the percentage of positive lymphocyte and granulocyte adhesion molecules. These patients also had significantly less progression of existing pressure ulcers as compared to patients receiving an isonitrogenous, nutrient-sufficient formula.

The results of this study appear to support the positive effect of PUFA on CAM expression in ICU patients. However, the study was limited by the fact that only circulating markers were measured. Immune cells in tissue and plasma do not necessarily reflect the same phenotype and may have differing responsiveness. However, it appears that nutritional support in general may play an important role in the treatment of wound healing and pressure ulcers and specific nutrients may further modulate the efficacy of nutrition. Our findings suggest that n-3-LC-PUFA may have a positive effect on wound healing and that this effect may be mediated by adhesiondependent mechanisms. We believe that our findings are novel and expand the therapeutic repertoire of fish oil in the critically ill.

In conclusion, we have presented our recent research in the field of nutrition in hospitalized elderly patients and in the critically ill. The main points which have become evident from this research include the following. 
TABLE 5: Effect of nutritional supplementation on pressure ulcer healing and adhesion molecules.

\begin{tabular}{|c|c|c|c|}
\hline Parameter & Study group & Control group & $P$ value \\
\hline $\begin{array}{l}\text { CD18 lymphocytes- (\%-) baseline to } \\
\text { day } 7 \text { of study }\end{array}$ & $\begin{array}{c}24.4 \pm 27.4 \text { to } \\
45.2 \pm 33.2 \\
\end{array}$ & $\begin{array}{c}48.1 \pm 38.1 \text { to } \\
33.1 \pm 24.1 \\
\end{array}$ & $<0.05$ \\
\hline $\begin{array}{l}\text { CD1la lymphocytes- (\%-) baseline to } \\
\text { day } 7 \text { of study }\end{array}$ & $\begin{array}{c}54.4 \pm 40.3 \text { to } \\
70.8 \pm 39\end{array}$ & $\begin{array}{c}61 \pm 43 \text { to } \\
68.7 \pm 35.6\end{array}$ & $<0.05$ \\
\hline $\begin{array}{l}\text { CD49b lymphocytes- (\%-) baseline to } \\
\text { day } 7 \text { of study }\end{array}$ & $\begin{array}{c}48.7 \pm 45.7 \text { to } \\
83.3 \pm 34.4\end{array}$ & $\begin{array}{c}47.3 \pm 46.8 \text { to } \\
39.1 \pm 42.1\end{array}$ & $<0.05$ \\
\hline $\begin{array}{l}\text { PUSH tool total score-baseline to day } 7 \text { of } \\
\text { study }\end{array}$ & 9.25 to 10.75 & 9.10 to 8.79 & $<0.05$ \\
\hline
\end{tabular}

PUSH: pressure ulcer scale for healing.

(1) Energy requirements are most accurately measured by indirect calorimetry.

(2) Repeated measurements show that energy demands are dynamic and change over the ICU or hospital stay.

(3) Providing adequate energy according to these measurements appears to have a beneficial effect on many outcome parameters.

(4) An integral component of our research has been the provision of nutrition as early in the ICU course as possible (preferably within the first 48 hours). In a recent meta-analysis, evaluation of clinical trials commencing enteral nutrition within $48 \mathrm{~h}$ of intensive care unit admission revealed a significant reduction in infectious complications [38]. A statistically significant mortality reduction was reported in metaanalysis of clinical trials commencing enteral nutrition within $24 \mathrm{~h}$ of ICU admission or catastrophic injury without inducing any significant harm; provision of early enteral nutrition also reduces overall hospital costs.

(5) Adequate provision of nutrition is achievable only when there is a dedicated nutrition team and the appropriate equipment and training.

(6) The addition of specialized nutritional support in the form of EPA + GLA may have additional outcome benefits for some patients with ALI/ARDS and aid in the healing and prevention of pressure sores.

Our research in the field of nutrition in the critically ill patient has been extended to involve an international study on the value of tight calorie control, an issue which remains controversial for many ICU practitioners. In addition, we are testing the benefit of specialized nutritional support, especially the use of omega-3-fatty acids, in a variety of clinical conditions including multitrauma, both in the acute setting and a possible effect on posttraumatic stress.

\section{Conflict of Interests}

The authors declare that there is no conflict of interests regarding the publication of this paper.

\section{References}

[1] K. G. Kreymann, M. M. Berger, N. E. P. Deutz et al., "ESPEN guidelines on enteral nutrition: intensive care," Clinical Nutrition, vol. 25, no. 2, pp. 210-223, 2006.

[2] D. K. Heyland, R. Dhaliwal, J. W. Drover, L. Gramlich, and P. Dodek, "Canadian clinical practice guidelines for nutrition support in mechanically ventilated, critically ill adult patients," Journal of Parenteral and Enteral Nutrition, vol. 27, no. 5, pp. 355-373, 2003.

[3] G. S. Doig, Evidence-Based Guidelines for Nutritional Support of the Critically Ill: Results of a Bi-National Guideline Development Conference, Australian and New Zealand Intensive Care Society (ANZICS), Carlton, Australia, 2005, http://www.guidelines .gov/.

[4] K. G. Kreymann, "Early nutrition support in critical care: a European perspective," Current Opinion in Clinical Nutrition and Metabolic Care, vol. 11, no. 2, pp. 156-159, 2008.

[5] J. M. Engel, J. Mühling, A. Junger, T. Menges, B. Kärcher, and G. Hempelmann, "Enteral nutrition practice in a surgical intensive care unit: what proportion of energy expenditure is delivered enterally?" Clinical Nutrition, vol. 22, no. 2, pp. 187-192, 2003.

[6] A. P. Marshall and S. H. West, "Enteral feeding in the critically ill: are nursing practices contributing to hypocaloric feeding?" Intensive and Critical Care Nursing, vol. 22, no. 2, pp. 95-105, 2006.

[7] S. A. McClave, L. K. Sexton, D. A. Spain et al., "Enteral tube feeding in the intensive care unit: factors impeding adequate delivery," Critical Care Medicine, vol. 27, no. 7, pp. 1252-1256, 1999.

[8] S. Villet, R. L. Chiolero, M. D. Bollmann et al., "Negative impact of hypocaloric feeding and energy balance on clinical outcome in ICU patients," Clinical Nutrition, vol. 24, no. 4, pp. 502-509, 2005.

[9] L. Rubinson, G. B. Diette, X. Song, R. G. Brower, and J. A. Krishnan, "Low caloric intake is associated with nosocomial bloodstream infections in patients in the medical intensive care unit," Critical Care Medicine, vol. 32, no. 2, pp. 350-357, 2004.

[10] D. Dvir, J. Cohen, and P. Singer, "Computerized energy balance and complications in critically ill patients: an observational study," Clinical Nutrition, vol. 25, no. 1, pp. 37-44, 2006.

[11] F. B. Cerra, M. R. Benitez, G. L. Blackburn et al., "Applied nutrition in ICU patients: a consensus statement of the American College of Chest Physicians," Chest, vol. 111, no. 3, pp. 769-778, 1997. 
[12] D. C. Frankenfield, W. A. Rowe, J. S. Smith, and R. N. Cooney, "Validation of several established equations for resting metabolic rate in obese and nonobese people," Journal of the American Dietetic Association, vol. 103, no. 9, pp. 1152-1159, 2003.

[13] P. Singer, R. Anbar, J. Cohen et al., "The tight calorie control study (TICACOS): a prospective, randomized, controlled pilot study of nutritional support in critically ill patients," Intensive Care Medicine, vol. 37, no. 4, pp. 601-609, 2011.

[14] V. Artinian, H. Krayem, and B. DiGiovine, "Effects of early enteral feeding on the outcome of critically ill mechanically ventilated medical patients," Chest, vol. 129, no. 4, pp. 960-967, 2006.

[15] C. A. Brauer, M. Coca-Perraillon, D. M. Cutler, and A. B. Rosen, "Incidence and mortality of hip fractures in the United States," The Journal of the American Medical Association, vol. 302, no. 14, pp. 1573-1579, 2009.

[16] A. Avenell and H. H. Handoll, "Nutritional supplementation for hip fracture aftercare in older people," Cochrane Database of Systematic Reviews, no. 2, 2005.

[17] G. Akner and T. Cederholm, "Treatment of protein-energy malnutrition in chronic nonmalignant disorders," The American Journal of Clinical Nutrition, vol. 74, no. 1, pp. 6-24, 2001.

[18] M. Hedstrom, O. Ljunggvist, and T. Cederholm, "Metabolism and catabolism in hip fracture patients: nutritional and anabolic intervention-a review," Acta Orthopaedica, vol. 77, no. 5, pp. 741-747, 2006.

[19] R. H. Houwing, M. Rozendaal, W. Wouters-Wesseling, J. W. J. Beulens, E. Buskens, and J. R. Haalboom, "A randomised, double-blind assessment of the effect of nutritional supplementation on the prevention of pressure ulcers in hip-fracture patients," Clinical Nutrition, vol. 22, no. 4, pp. 401-405, 2003.

[20] H. van Hoang, F. A. Silverstone, S. Leventer, G. P. Wolf-Klein, and C. J. Foley, "The effect of nutritional status on length of stay in elderly hip fracture patients," Journal of Nutrition, Health and Aging, vol. 2, no. 3, pp. 159-161, 1998.

[21] R. Anbar, Y. Beloosesky, J. Cohen et al., “Tight Calorie Control in geriatric patients following hip fracture decreases complications: a randomized, controlled study," Clinical Nutrition, vol. 33, no. 1, pp. 23-28, 2014.

[22] G. R. Bernard, A. Artigas, K. L. Brigham et al., "The AmericanEuropean Consensus Conference on ARDS: definitions, mechanisms, relevant outcomes, and clinical trial coordination," American Journal of Respiratory and Critical Care Medicine, vol. 149, no. 3, pp. 818-824, 1994.

[23] M. A. Matthay, T. Nuckton, and B. Daniel, "Alveolar epithelial barrier: acute lung injury," in Year Book of Intensive Care and Emergency Medicine 2000, J. L. Vincent, Ed., pp. 189-205, Springer, Berlin, Germany, 2000.

[24] P. Mancuso, J. Whelan, S. J. DeMichele, C. C. Snider, J. A. Guszcza, and M. D. Karlstad, "Dietary fish oil and fish and borage oil suppress intrapulmonary proinflammatory eicosanoid biosynthesis and attenuate pulmonary neutrophil accumulation in endotoxic rats," Critical Care Medicine, vol. 25, no. 7, pp. 11981206, 1997.

[25] P. Mancuso, J. Whelan, S. J. DeMichele et al., "Effects of eicosapentaenoic and $\gamma$-linolenic acid on lung permeability and alveolar macrophage eicosanoid synthesis in endotoxic rats," Critical Care Medicine, vol. 25, no. 3, pp. 523-532, 1997.

[26] P. Singer, M. Theilla, H. Fisher, L. Gibstein, E. Grozovski, and J. Cohen, "Benefit of an enteral diet enriched with eicosapentaenoic acid and gamma-linolenic acid in ventilated patients with acute lung injury,' Critical Care Medicine, vol. 34, no. 4, pp. 1033-1038, 2006.

[27] P. B. Keller, J. Wille, B. van Ramshorst, and C. van der Werken, "Pressure ulcers in intensive care patients: a review of risks and prevention," Intensive Care Medicine, vol. 28, no. 10, pp. 1379$1388,2002$.

[28] M. Arnold and A. Barbul, "Nutrition and wound healing," Plastic and Reconstructive Surgery, vol. 117, supplement 7, pp. 42S-58S, 2006.

[29] E. S. M. Shahin, T. Dassen, and R. J. G. Halfens, "Pressure ulcer prevalence and incidence in intensive care patients: a literature review," Nursing in Critical Care, vol. 13, no. 2, pp. 71-79, 2008.

[30] H. Terekeci, Y. Kucukardali, C. Top, Y. Onem, S. Celik, and Ç. Öktenli, "Risk assessment study of the pressure ulcers in intensive care unit patients," European Journal of Internal Medicine, vol. 20, no. 4, pp. 394-397, 2009.

[31] P. Teller and T. K. White, "The physiology of wound healing: injury through maturation," Surgical Clinics of North America, vol. 89, no. 3, pp. 599-610, 2009.

[32] G. C. Gurtner, S. Werner, Y. Barrandon, and M. T. Longaker, "Wound repair and regeneration," Nature, vol. 453, no. 7193, pp. 314-321, 2008.

[33] J. M. Cruse, H. Wang, R. E. Lewis et al., "Cellular and molecular alterations in spinal cord injury patients with pressure ulcers: a preliminary report," Experimental and Molecular Pathology, vol. 72, no. 2, pp. 124-131, 2002.

[34] T. K. Hulsey, J. A. O'Neill, W. R. Neblett, and H. C. Meng, "Experimental wound healing in essential fatty acid deficiency," Journal of Pediatric Surgery, vol. 15, no. 4, pp. 505-508, 1980.

[35] K. S. Bjerve, "n-3 fatty acid deficiency in man," Journal of Internal Medicine, vol. 225, no. S731, pp. 171-175, 1989.

[36] M. Theilla, B. Schwartz, Y. Zimra et al., "Enteral n-3 fatty acids and micronutrients enhance percentage of positive neutrophil and lymphocyte adhesion molecules: a potential mediator of pressure ulcer healing in critically ill patients," The British journal of nutrition, vol. 107, no. 7, pp. 1056-1061, 2012.

[37] E. George-Saintilus, B. Tommasulo, C. E. Cal et al., " Pressure ulcer PUSH score and traditional nursing assessment in nursing home residents: do they correlate?" Journal of the American Medical Directors Association, vol. 10, no. 2, pp. 141-144, 2009.

[38] P. Singer, G. S. Doig, and C. Pichard, "The truth about nutrition in the ICU," Intensive Care Medicine, vol. 40, no. 2, pp. 252-255, 2014. 


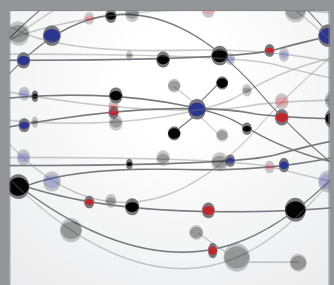

The Scientific World Journal
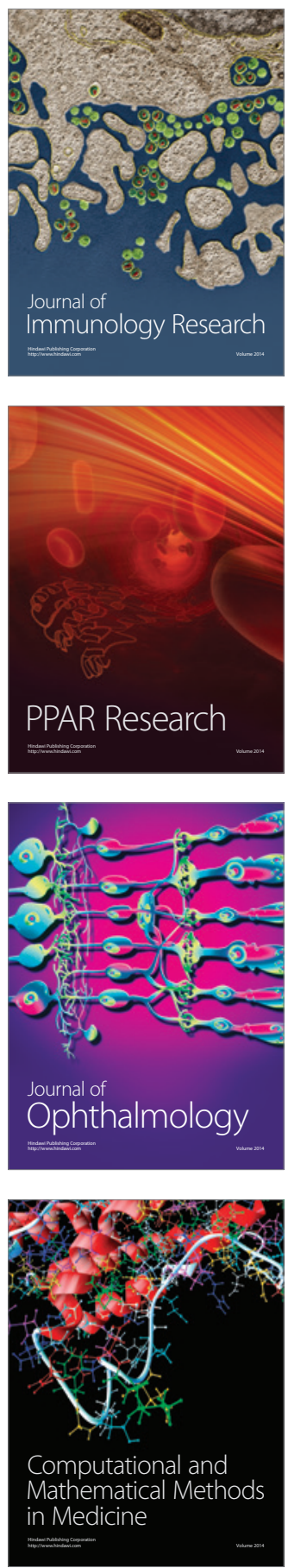

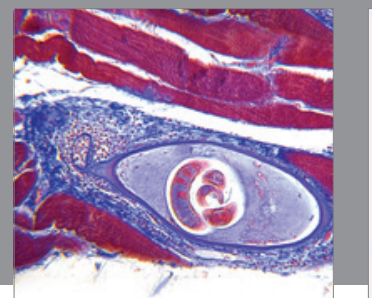

Gastroenterology

Research and Practice
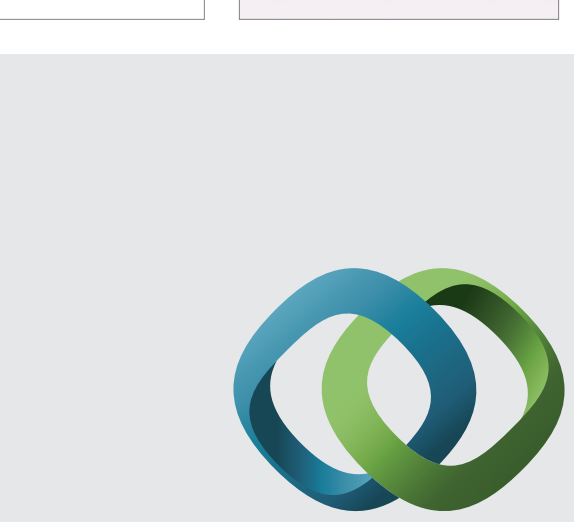

\section{Hindawi}

Submit your manuscripts at

http://www.hindawi.com
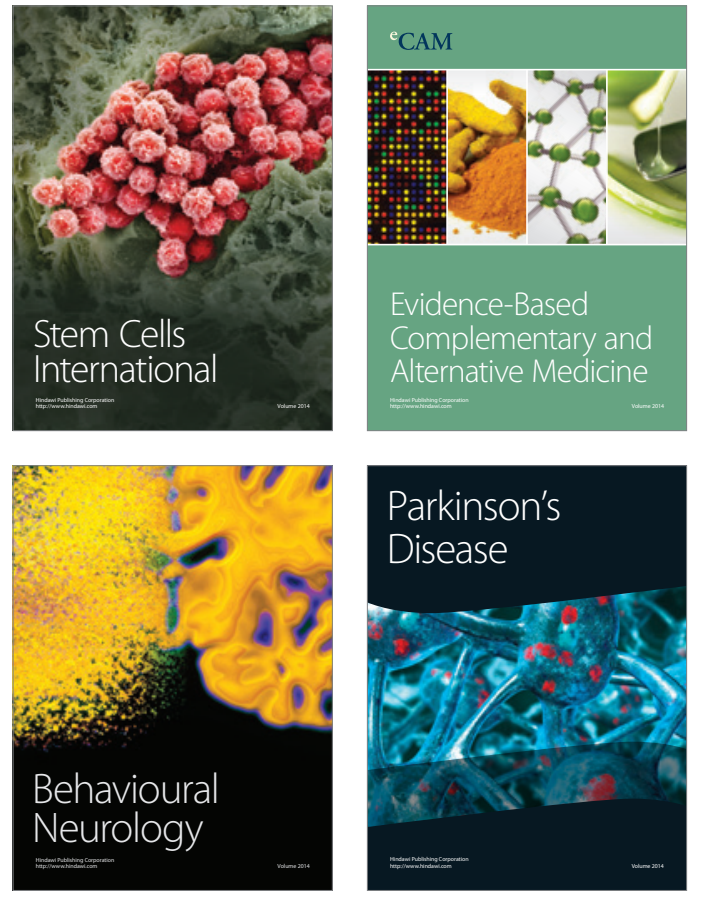
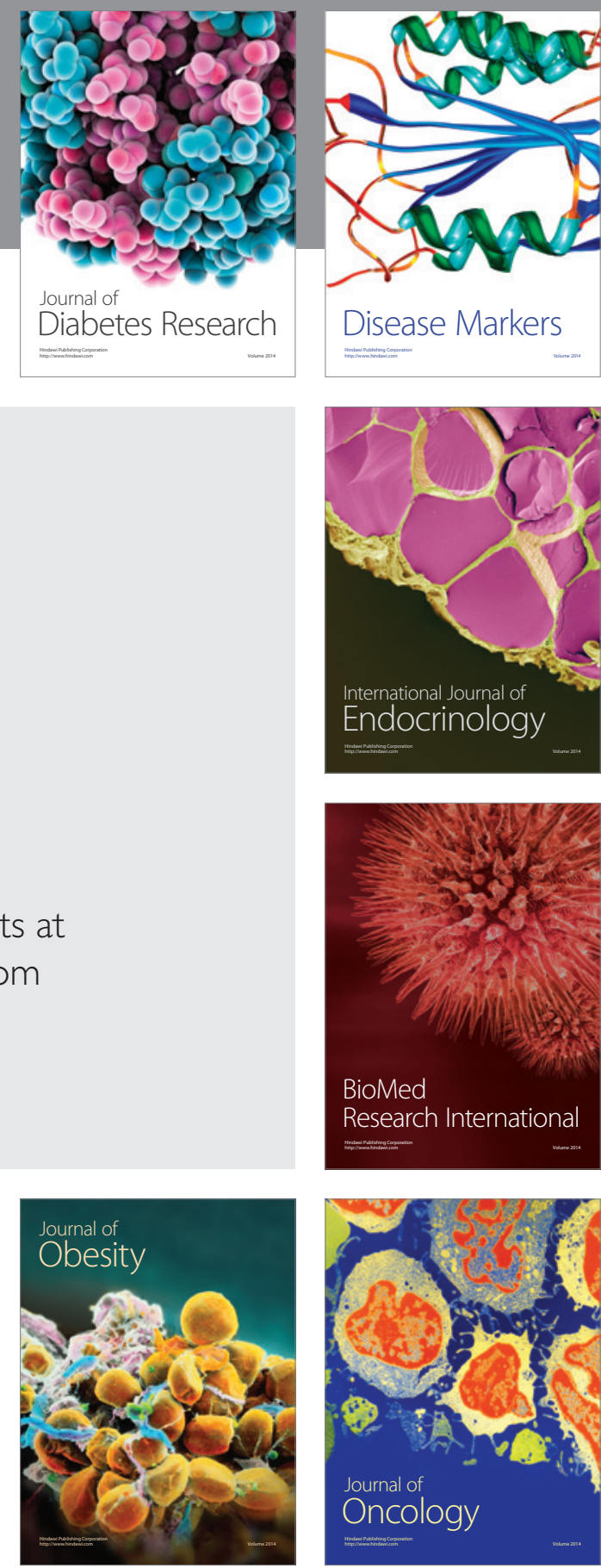

Disease Markers
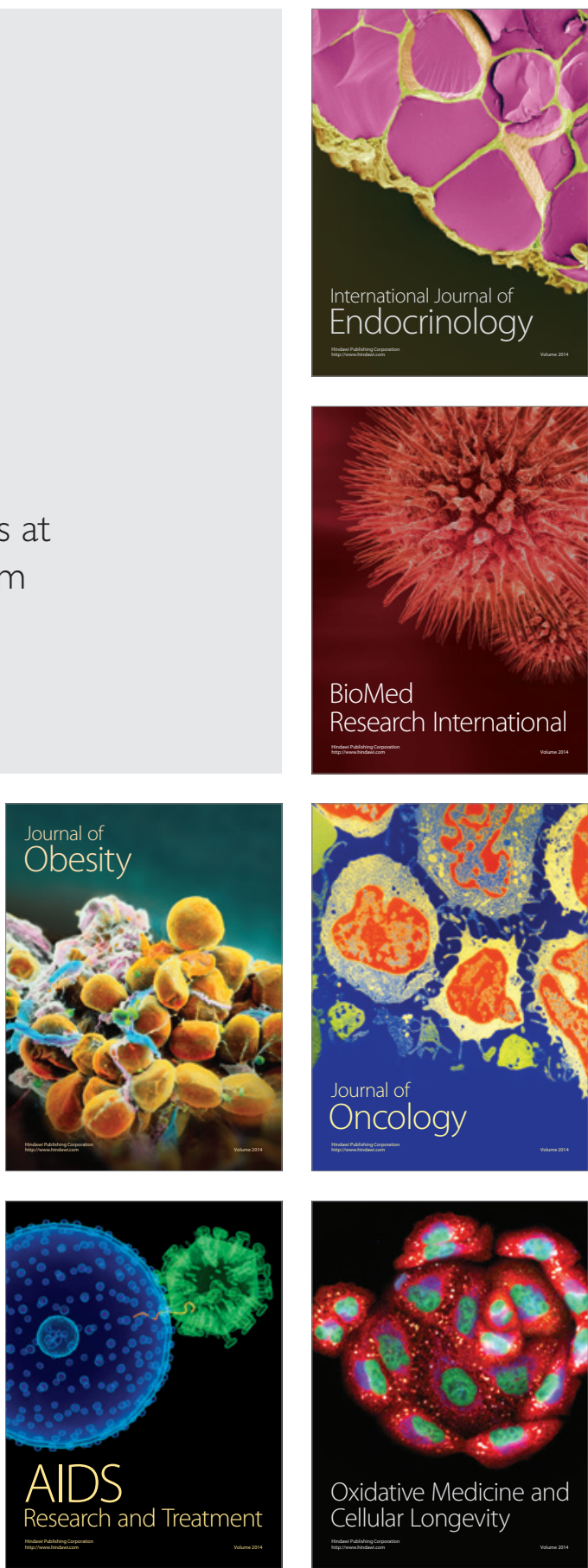